\title{
Evaluation of Some Mulberry Varieties for Rearing Performance and Economic Traits of Silkworm (Bombyx Mori L)
}

\author{
S. G. Pakhale, P. A. Bothikar, U. L. Lande, S. A. Shendage, \\ Department of Entomology, College of Agriculture, V.N.M.K.V, Parbhani-431401 Maharashtra, India. \\ M.Sc. (Agri.). Assistant Professor Department of Entomology, C.S.M.S.S. College of Agriculture, Kanchanwadi, \\ Aurangabad- 413 001, Maharashtra, India. \\ Ph. D. Assistant Professor Department of Entomology, V.N.M.K.V College of Agriculture, Parbhani, - 413 401, \\ Maharashtra, India. \\ M.Sc. (Agri.). Assistant Professor Department of Entomology, C.S.M.S.S. College of Agriculture, Kanchanwadi, \\ Aurangabad- 413 001, Maharashtra, India.
}

\begin{abstract}
The studies on Disease free eggs of silkworm hybrids MY 1 x CSR 2 were utilized. The treatments were V-1, Kanva-2, BER-1, BER-779, Mizosava, A-1, S-30, S-34, S-36, and S-54. Observations on the different economic traits of silkworm Bombyx mori L. were taken. Larval weight varied in the range of $33.77 \mathrm{~g}$ to 40.67 g. Variety V-1 (40.67 g), Larval duration was observed in the range of 21.04 days to 22.28 days. Variety BER-1 (21.04 days), Single cocoon weight $1.664 \mathrm{~g}$ to $1.863 \mathrm{~g}$. The highest single cocoon weight was V-1 (1.863 g), Single shell weight $0.297 \mathrm{~g}$ to $0.364 \mathrm{~g}$. Maximum shell weight $V-1(0.364 \mathrm{~g})$, Shell percentage 17.60 per cent to 19.82 per cent. Maximum yield variety $\mathrm{V}-1(18.63 \mathrm{~kg})$, was observed significantly superior, Cocoon filament length in the range of $680.00 \mathrm{~m}$ to $836.66 \mathrm{~m}$. Longest filament length variety $V-1(836.66 \mathrm{~m})$. These findings will help the sericulturists in finding suitable variety for getting more economic returns from silkworm rearing. It is observed that V-1 is becoming popular in Marathwada region.

Key Words : Fecundity, Larval duration, Deneir, Cocoon yield, Shell ratio, Bombyx mori L.
\end{abstract}

\section{Introduction}

Since time immemorial, silk has embraced the Indian ways of life, starting from the days of Vedas of this day. It plays various roles in our life from time to time. In nature, insect produces or collect different products like silk, honey, beeswax, shellac, paints, medicine etc. Among these silk production is gaining importance. Sericulture is an agro-based rural industry combining the features of agriculture and village industry. Today despite of man-made fibre, natural silk is durable. Its softness and beauty makes it a very attractive wearing. By producing self employment in rural areas, not only the rural migration is arrested but also the cottage and small industries get established in rural India. The silk production in the world with 11,7042 MT of silk. India enjoys the distinction of being the only country in the world where all four silkworms viz., mulberry silkworm (Bombyx mori L.), tasar silkworm (Antheraea paphia L.), eri silkworm (Attacus ricinii) and muga silkworm (Antheraea assama) are commercially raised. In India, about 95 per cent production is from mulberry silk (Anonymous, 1983).

\section{Material And Methods}

The present investigation was undertaken during September-October 2007 to evaluate the effect of different mulberry varieties on rearing performance and economic traits of silk worms (Bombyx mori). Krishnaswami (1978) described the improved technology of silkworm rearing and it was adopted in this investigation. The newly hatched larvae were fed with chopped pieces of fresh mulberry leaves of ten different varieties viz., V-1, Kanva-2, BER-1, BER-779, Mizosava, A-1, S-30, S-34, S-36 and S-54. The leaves were chopped into small pieces of $0.5 \mathrm{~cm}$ and sprinkled over the newly hatched worms for their feeding. The feeding was given four times in a day. The rearing trays were cleaned daily as per recommended times.

After full development, the ripe worms were identified, as they looked translucent with creamy colour. The ripe worms ceased to eat, crawled towards periphery of the trays and tried to spin the cocoons, were handpicked and put on the Chandrika. The worms spun the cocoons within 48 to 72 hours. The pupae remained inside the cocoons till emergence.

The harvesting of cocoon was carried out on fifth day of release of worms on Chandrika. Randomly selected ten cocoons of each treatment were used for recording cocoon parameters.

The observations were recorded on larval duration; weight of 10 matured larvae, single cocoon weight, single shell weight, and yield per 10,000 larvae brushed and cocoon filament length.

The data thus collected were statistically analysed and the results were recorded 


\section{Results And Discussion \\ Feeding Effect Of Different Mulberry Varieties On Silkworm. Larval Weight (G)}

The data presented in Table. Revealed larval that weight of 10 mature larvae varied in the range of $33.77 \mathrm{~g}$ to $40.67 \mathrm{~g}$. Variety V- 1 ( $40.67 \mathrm{~g})$ was observed significantly superior among tested varieties, which was followed by BER-1 (39.69 g), Kanva-2 (39.59 g) and they were at par each other. Lowest larval weight was recorded in larvae fed on leaves of BER-779 (33.77 g) which was significantly lower as compare to all other varieties of mulberry.

Comparative merits of five varieties of mulberry Kosen, Kanva-2, Rosa, MR-2 and S-54 on the cocoon of two bivoltine races (NB4D2 and Kalimpong A) and a multivoltine race (Hosa Mysore) were assessed. MR-2 showed higher values in larval weight and single cocoon weight in all the three races followed by S-54 and Kanva-2 varieties (Pillai et al., 1981). Larval weight of silkworm Bombyx mori L. varied in the range of $30.61 \mathrm{~g}$ to 34.80 g. Variety V-1 $(34.80 \mathrm{~g})$ was observed significantly superior among tested varieties Which was followed by Kanva-2 (34.67 g), Mizosava (34.59 g), BER-1 (34.51 g) and S-34 (34.40 g) whereas lowest larval weight was recorded in larvae fed on leaves of P-16 (30.61 g) variety of mulberry. Work was carried out to evaluate rearing performance and economic traits of silkworm. (Patil, 2004).

\section{Larval Duration (Days)}

The data on the larval duration of silkworm Bombyx mori L. are presented in Table. Larval duration was observed in the range of 21.04 days to 22.28 days. In variety BER-1 (21.04 days) recorded significantly lowest larval duration over rest of the treatments.

It revealed that larval duration was observed in the range of 22.13 days to 23.27 days. Variety Kanva2 (22.13 days) recorded significantly lowest larval duration over rest of the treatments. Kanva-2 (22.13 days) and V- 1 (22.23 days) were at par with each other. Highest larval duration was recorded in larvae fed on leaves of S 54 (23.27 days) variety of mulberry. Work was carried out to evaluate rearing performance and economic traits of silkworm. (Gawade, 2006).

\section{Single Cocoon Weight (G)}

Results revealed single cocoon weight of silkworm Bombyx mori L. varied in the range of $1.664 \mathrm{~g}$ to $1.863 \mathrm{~g}$. The highest single cocoon weight was observed in the larvae fed on leaves of V-1 (1.863 g) followed by BER-1(1.855 g) and S-54 $(1.817 \mathrm{~g}), \mathrm{S}-36(1.811 \mathrm{~g}), \mathrm{S}-30(1.803 \mathrm{~g})$ which were at par with each other. Lowest single cocoon weight was recorded in larvae fed on BER-779 (1.664 g) variety of mulberry.

It is reported that Single cocoon weight of silkworm Bombyx mori L. larvae varied in the range of $1.604 \mathrm{~g}$ to $2.307 \mathrm{~g}$. The highest single cocoon weight was observed in the larvae fed on leaves of V-1 $(1.863 \mathrm{~g})$ followed by BER-1 $(1.855 \mathrm{~g})$ and S-54 $(1.817 \mathrm{~g}), \mathrm{S}-36(1.811 \mathrm{~g}), \mathrm{S}-30(1.803 \mathrm{~g})$ which were at par with each other. Lowest single cocoon weight was recorded in larvae fed on BER-779 $(1.664 \mathrm{~g})$ variety of mulberry. Work was carried out to evaluate rearing performance and economic traits of silkworm (Patil, 2004).

\section{Single Shell Weight (G)}

The data on single shell weight of silkworm Bombyx mori L. are presented in Table. Result revealed that single shell weight was observed in the range of $0.297 \mathrm{~g}$ to $0.364 \mathrm{~g}$. Maximum shell weight was recorded by larvae fed on leaves of V-1 $(0.364 \mathrm{~g})$ followed by S-36 $(0.345 \mathrm{~g})$ which were at par each other. Whereas minimum shell weight was recorded in larvae fed on the leaves of BER-779 $(0.297 \mathrm{~g})$ which was significantly lower compare to other varieties of mulberry. Maximum weight of single shell was found in silkworm reared on mulberry variety S-54 (0.239 g) and next superior was variety V-1 (0.234 g) (Anonymous, 2001).

Single shell weight of silkworm Bombyx mori L. Treatment V-1 and S-36 were at par with each other. Whereas minimum shell weight was recorded in larvae fed on the leaves of Mizosava $(0.376 \mathrm{~g})$ variety of mulberry. Work was carried out to evaluate rearing performance and economic traits of silkworm (Gawade, 2006).

\section{Total Cocoon Yield Per 10,000 Larvae Brushed (Kg)}

Table showed the effect of different mulberry varieties on the cocoon yield per 10,000 larvae brushed. Results revealed that cocoon yield per 10000 larvae brushed varied between the range of $16.64 \mathrm{~kg}$ to $18.63 \mathrm{~kg}$. Maximum yield was obtained in the variety V-1 (18.63 kg) which was followed by BER-1 $(18.5 \mathrm{~kg}), \quad \mathrm{S}-54$ $(18.17 \mathrm{~kg}), \mathrm{S}-36(18.11 \mathrm{Kg})$ and $\mathrm{S}-30(18.03 \mathrm{Kg})$ which were at par with each other whereas lowest yield was obtained from larvae fed on leaves of BER-779 $(16.64 \mathrm{~kg}$ ) variety of mulberry.(Anonymous, 2001). 
Cocoon yield per 10,000 larvae brushed varied in the range of $16.04 \mathrm{~kg}$ to $23.07 \mathrm{~kg}$. Maximum yield was observed in the variety Kanva-2 $(23.07 \mathrm{~kg})$ which was followed by V-1 $(22.24 \mathrm{~kg})$. Whereas lowest yield was obtained from larvae fed on leaves of P-16 $(16.04 \mathrm{~kg})$ variety of mulberry. Work was carried out to evaluate rearing performance and economic traits of silkworm (Patil, 2004).

\section{Cocoon Filament Length (M) Of Silkworm}

The data on cocoon filament length of silkworm (Bombyx mori L.) are presented in Table . Result revealed that cocoon filament length was recorded in the range of $680 \mathrm{~m}$ to $836.66 \mathrm{~m}$. Longest filament length was recorded in larvae fed on variety V-1 $(836.66 \mathrm{~m})$ followed by Kanva-2 $(798.33 \mathrm{~m}), \mathrm{S}-54(780.00 \mathrm{~m})$ and S$36(775.00 \mathrm{~m})$ which were at par with each other. Whereas shortest cocoon filament length was recorded in larvae fed on leaves of BER $-779(680.00 \mathrm{~m})$ variety of mulberry.

Cocoon filament length of silkworm Bombyx mori L. was recorded in the range of $676 \mathrm{~m}$ to $816.6 \mathrm{~m}$. Longest filament length was recorded in larvae fed on variety S-54 $(816.6 \mathrm{~m})$ followed by BER-1 $(810 \mathrm{~m})$. Whereas shortest cocoon filament length was recorded in larvae fed on leaves of P-16 (676.6 m) variety of mulberry. Work was carried out to evaluate rearing performance and economic traits of silkworm (Patil, 2004).

\section{Reference}

[1]. Anonymous. 1983. Varietal effect on the development and economic characters of silkworm, Bombyx mori L. Agriculture Research Sub-committee Report of Sericulture Research Unit, Department of Entomology, MAU, Parbhani.

[2]. Anonymous. 2001. Evaluation of mulberry varieties for rearing performance and economic traits of silkworm Bombyx mori : L. Annual Report, Sericulture Research Unit, MAU, Parbhani 8-10

[3]. Gawade, B.V. 2006. Evaluation of mulberry varieties for rearing performance and their different economic traits on silkworm (Bombyx mori). M.Sc. (Agri.) Thesis, MAU, Parbhani.

[4]. Giridhar, K.; Lakshmanan, S; Benchamin K.V. and Sengupta, K. 1990. Performance of local and Kanva-2 mulberry varieties in respect of leaf and cocoon yields at farmers level. Indian J. Sericulture. 29(2): 219-226.

[5]. Krishnaswami, S. 1971. Silkworm feeding trials for evaluating the quality of mulberry leaves as influenced by variety, spacing and nitrogen fertilization. Indian J. Seri. 19(1): 79-89.

[6]. Krishnaswami, S. 1978. New technology of silkworm rearing. Bull. No. 3, CSR and TI, Mysore.

[7]. Patil, S.N. 2004. Evaluation of mulberry varieties for rearing performance and their different economic traits on silkworm (Bombyx mori). M.Sc. (Agri.) Thesis, MAU, Parbhani.

[8]. Pillai, V.S.; Krishnaswami, S.; Bhat, D.V. and Ranganath, B.K. 1981. Varietal effect on the development and economic characters of Bombyx mori L. Proceedings of Sericulture Symposium and Seminar, TNAU, Coimbatore : 137-140.

[9]. Tayade, D.S., 1984. A comparative performance of pure silkworm races under Marathwada conditions. A paper presented at Agriculture Research Sub-committee, MAU, Parbhani.

[10]. Venugopala Pillai, S.; Krishnaswami, S.; Bhat, D.V. and Ranganath, B.K., 1981. Varietal effect of the development and economic characters of Bombyx mori L. Proceeding of Sericulture Symposium and Seminar, TNAU, Coimbatore, 137-140.

Table1. Feeding Effect Of Different Mulberry Varieties On Silkworm.

\begin{tabular}{|l|l|l|l|l|l|l|l|}
\hline $\begin{array}{l}\text { Sr. } \\
\text { No. }\end{array}$ & Treatments & $\begin{array}{l}\text { Larval } \\
\text { weight }(\mathbf{g})\end{array}$ & $\begin{array}{l}\text { Larval } \\
\text { duration } \\
\text { days) }\end{array}$ & $\begin{array}{l}\text { Single } \\
\text { cocoon } \\
\text { weight }(\mathbf{g})\end{array}$ & $\begin{array}{l}\text { Single shell } \\
\text { weight }(\mathbf{g})\end{array}$ & $\begin{array}{l}\text { Total Cocoon } \\
\text { yield Per (Kg) }\end{array}$ & $\begin{array}{l}\text { Cocoon } \\
\text { filament } \\
\text { length } \\
(\mathbf{m})\end{array}$ \\
\hline 1 & \multicolumn{1}{|c|}{ V-1 } & 40.67 & 22.08 & 1.86 & 0.36 & 18.63 & 836.66 \\
\hline 2 & Kanva-2 & 39.59 & 22.04 & 1.78 & 0.33 & 17.80 & 798.33 \\
\hline 3 & BER-1 & 39.69 & 21.04 & 1.86 & 0.34 & 18.55 & 718.33 \\
\hline 4 & BER-779 & 33.77 & 22.26 & 1.66 & 0.30 & 16.64 & 680.00 \\
\hline 5 & Mizosava & 35.21 & 22.26 & 1.71 & 0.32 & 17.12 & 700.00 \\
\hline 6 & A-1 & 37.15 & 22.03 & 1.72 & 0.33 & 17.21 & 705.00 \\
\hline 7 & S-30 & 36.54 & 22.28 & 1.80 & 0.33 & 18.03 & 696.66 \\
\hline 8 & S-34 & 36.31 & 22.26 & 1.77 & 0.33 & 17.65 & 705.00 \\
\hline 9 & S-36 & 38.11 & 22.03 & 1.81 & 0.35 & 18.11 & 775.00 \\
\hline 10 & S-54 & 36.31 & 22.03 & 1.82 & 0.32 & 18.17 & 780.00 \\
\hline & SE \pm & 0.41 & 0.02 & 0.02 & 0.007 & 0.203 & 21.795 \\
\hline & CD at $5 \%$ & 1.22 & 0.51 & 0.06 & 0.019 & 0.602 & 64.658 \\
\hline
\end{tabular}

